\title{
PEREMPUAN PEMIMPIN DI GEREJA ISA ALMASIH: TINJAUAN DARI PERSPEKTIF TEOLOGI FEMINIS DAN RENEWAL THEOLOGY
}

\author{
Minggus M. Pranoto \\ Sekolah Tinggi Theologia Abdiel \\ minggusminarto@gmail.com
}

\begin{abstract}
This article discusses "Woman as Leader in the Church of Isa Almasih (Christ Jesus)" from the perspective of Feminist Theology and Renewal theology. The writer tries to find the convergence and divergence points of both perspective above, including its method and interpretation in observing the theological basis about the woman as leader. The binder of the big theme to discuss this article from both perspective is the Holy Spirit as the Giver of freedom and equality. From this perspective, the writer tries to make a new proposal about how to give theological inputs to remodel gender stereotype in the context of the Church.
\end{abstract}

Keywords: Woman, Leader, Feminist Theology, Renewal Theology, the Holy Spirit.

\section{Pendahuluan}

Gereja-gereja Pentakosta ${ }^{1}$, termasuk Gereja Isa Almasih di dalamnya, memberikan kesempatan kepada perempuan dalam tugas-tugas pelayanan sebagai pengkhotbah, pengajar, penyembuh, penginjil, dan sebagainya. Namun Gereja-gereja Pentakostal sulit sekali membuka ruang adanya perempuan pemimpin.Padahal gerakan pentakostalisme awal di bawah pengaruh William J. Seymour menekankan kesetaraan laki-laki dan perempuan dalam menerima panggilan dan mengerjakan tugas pelayanan. Tak jarang perempuan menempati posisi penting dalam konteks pelayanan gerejawi di bawah kepemimpinan Seymour. Gereja Isa Almasih, termasuk Gereja-gereja Pentakostal pada umumnya, tampaknya melupakan akar spiritualitas pentakostalisme awal yang dibangun oleh William J. Seymour.

1 Arti Pentakosta mencakup juga untuk gerakan seperti Pentakosta klasik, Pentakosta baru, Karismatik, Karismatik Baru yang rata-rata pada umumnya mempunyai konsep yang kurang lebih sama tentang kepemimpinan perempuan. Oleh karena itu dalam tulisan ini hanya disebut Pentakosta saja (istilah Indonesia untuk Pentakosta disebut Pantekosa). Aliran Pentakosta telah menampilkan "multi wajah" dalam berbagai gerakan di atas yang saling tumpang tindih sekarang ini. Misalnya ada gereja Pentakosta yang tidak menekankan bahasa roh lagi, sedangkan di gereja-gereja Karismatik tertentu ada penekanan bahasa roh. Ada teologi Pentakosta yang mencampurkan teologinya dengan pengajaran teologi kemakmuran dsb. 
Tulisan ini akan membahas permasalahan di atas dari dua disiplin keilmuan yaitu Teologi Feminis dan Renewal Theology (Teologi Pembaruan). Saya berkeinginan untuk mencari titik-titik temu dan beda dari dua disiplin itu, termasuk metode dan tafsirnya dalam menyoroti dasar-dasar teologis tentang perempuan pemimpin. Tema besar pengikat untuk membahas hal tersebut adalah Roh Kudus sebagai pemberi kebebasan dan kesetaraan. Kemudian dari tinjauan dua disiplin keilmuan tersebut, saya akan mencoba membuat tawaran baru tentang bagaimana memberikan masukan secara teologis untuk merombak stereotip gender dalam Gereja Isa Almasih secara khususnya.

\section{Akar Spiritualitas Pentakostalisme Awal dan Perubahan Orientasinya}

Kisah Para Rasul 2:17 berbunyi, “... Aku akan mencurahkan Roh-Ku ke atas semua manusia; maka anak-anakmu laki-laki dan perempuan akan bernubuat ...” Ayat ini menjadi salah satu nas penting untuk menekankan adanya kesetaraan antara laki-laki dan perempuan dari perspektif pneumatologis. Baik laki-laki maupun perempuan sama-sama dapat menjadi agen Allah untuk menyatakan kebenaran-Nya di dunia ini. Bagi William J. Seymour, seorang kulit hitam keturunan Afrika-Amerika dan tokoh gerakan Pentakosta awal pada tahun 1906 di Amerika, nas tersebut dihidupi sungguh-sungguh dalam pelayanannya. Ia, melalui lembaga the Azusa Street Mission yang didirikannya, melibatkan perempuan berkulit putih dan hitam dalam berbagai pergerakan misi Kristen tidak saja di Amerika tetapi juga melalui misi ke seluruh dunia. Valerie C. Cooper mengatakan, "William J. Seymour, the African American who headed the Azusa Street Mission during its most influential early years, was surrounded by women - both black and white-who preached, operated in multiple gifts of the Spirit, and enthusiastically carried the message of Azusa and Pentecostalism around the globe." ${ }^{2}$ Kepemimpinan Seymour juga bercorak partisipatif yang membuka diri bagi laki-laki dan perempuan untuk terlibat dalam misi pelayanan. ${ }^{3}$ Mungkin dapat saja kita mengatakan bahwa gerakan awal ini menggambarkan proto feminist movement dalam tubuh pentakostalisme awal yang melakukan konter budaya terhadap masyarakat rasis dan patriarkat di Amerika waktu itu.

\footnotetext{
${ }^{2}$ Valerie C. Cooper, "Laying the Foundations for Azusa Black Women and Public Ministry in the Nineteenth Century", in Afro-Pentecostalism Black Pentecostal and Charismatic Christianity in History and Culture, peny. Amos Yong and Estrelda Y. Alexandera (New York and London: New York University Press, 2011), 65.

${ }^{3}$ Cecil M. Robeck Jr., The Azusa Street Mission and Revival: The Birth of the Global Pentecostal Movement (Nashville: Nelson Reference and Electronic, 2006), 14. Dikutip dalam Cooper, "Laying the Foundation", 65.
} 
Begitu fenomenalnya gerakan Azusa Street yang dipelopori Seymour ini maka para teolog Pentakostal seperti W. J. Hollenweger, Allan Anderson, Amos Yong, serta lainlainnya mengesampingkan tokoh gerakan pentakostalisme yang lebih awal yaitu bernama Charles F. Parham karena ia dianggap sangat rasis dan sektarian. Secara historis memang Parham sebagai cikal-bakal gerakan pentakostalisme awal yang di mulai di sebuah Sekolah Alkitab di Topeka, Kansas dan akhirnya berpuncak pada peristiwa spektakuler di Azusa Street yang dimotori oleh Seymour, yang adalah murid Parham. ${ }^{4}$ Tetapi bagi para teolog Pentakostal masa kini, Seymour adalah pendiri ideologis pentakostalisme. Hal tersebut karena ia telah memberi makna spiritualitas yang holistik daripada sekadar mengkaitkan pentakostalisme dengan baptisan Roh Kudus dan initial evidence-nya bahasa lidah (speaking in tongues) sebagaimana ditekankan oleh Parham. Setuju dengan Hollenweger, Allan Anderson mengatakan bahwa:

Parham represents a narrow ideology and an emphasis on a religious experience of speaking in tongues, where Seymour represents 'the reconciling Pentecostal experience' and 'a congregation where everybody is a potential contributor to the liturgy'. Seymour's Pentecostalism is 'the oral missionary movement, with spiritual power to overcome racism and chauvinism'.,5

Pentakostalisme Seymour jika ditinjau dari pendekatan realgeschichtliche, menurut Hollenweger, dipengaruhi oleh dua hal yakni pertama dari the Catholic Spirituality dari gerakan the American Holiness Movement dengan tokoh pionirnya John Wesley; dan kedua dari the black oral spirituality. ${ }^{6}$ Yang menarik, konsep kekudusan dari pengaruh yang pertama ini tidak dipahami dalam pengertian sempit atau individualistik yang berbicara soal kesalehan pribadi terlepas dari kesalehan sosial, tetapi "For the Americans (as for Wesley), holiness included their social and political pioneering work: such as inviting black and female students to their educational institutions and a plan for world peace through a worldwide peace-organization similar to the present-day United Nations." Hal yang lebih spesifik lagi dapat dijelaskan bahwa sebenarnya pengaruh teologi

${ }^{4}$ Ada surat yang ditulis oleh T. Barratt - saksi sejarah - tentang kebangunan rohani di Azusa Street yang mengatakan bahwa, "The Apostolic Faith Movement. Chas. F. Parham, Projector: W.J. Seymour. Pastor (Oct. 1906)." Ini dicatat di Bloch-Hoell II, hal. 48. Dalam Walter J. Hollenweger, The Pentecostals (Peabody, MA: Hendrickson Publishers, 1972), 27 khususnya di catatan-catatan nomor 22.

5 Allan Anderson, An Introduction to Pentecostalism: Global Charismatic Christianity. (Cambridge: Cambridge University Press, 2004), 270.

${ }^{6}$ Walter J. Hollenweger, "Priorities in Pentecostal Research: Historiography, Missiology, Hermeneutics, and Pneumatology", dikutip dalam Experiences of the Spirit: Conference on Pentecostal and Charismatic Research in Europe at Utrecht University 1989, peny. Jan A.B. Jongeneel (Frankfurt am Main: Peter Lang,1989), 8.

${ }^{7}$ Ibid., 8 . 
kekudusan itu datangnya dari sebuah kelompok gerakan kekudusan yang disebut "Evening Light Saints" yang berarti "spiritual night was soon about to fall on humanity, during the Church would provide the only light." ${ }^{\prime 8}$ Gerakan ini-termasuk di bawah payung besar gerakan kekudusan Wesley-disuarakan oleh Daniel S. Warner di tahun 1880 dan selanjutnya diteruskan oleh the Church of God di kota Anderson, Indiana. Menurut Cooper, Seymour pernah bersentuhan dengan kelompok ini saat ia menetap di Indianapolis. Kesan Seymour yang mendalam terhadap gerakan tersebut adalah tentang pengajaran eskatologipra-milenialisme yang intinya, sebagaimana dikatakan oleh Robeck, sebagai berikut: "The Evening Light Saints taught that a 'new age of the Christian church, the Evening Light (named for Zech. 14:7 'at evening time it shall be light'), was restoring the Church of the apostles." ${ }^{\text {'9 }}$ Lebih lanjut ia menambahkan:

In the 1890s the Evening Light Saints was one of the few groups in which blacks and whites were treated equally and gifted women were encouraged to preach. ... When William J. Seymour ultimately arrived in Los Angeles [Azusa], he was as committed to a policy of non-sectarianism, the equality of the races, and the equality of women and men as Warner was. ${ }^{10}$

Sedangkan pengaruh kedua terhadap pentakostalisme adalah dari the black oral spirituality yang terfokus pada warisan kulit hitam mengenai negro spirituals dan negro music. Keduanya mengajar tentang spiritualitas yang melampaui dari sekadar berbahasa lidah, tetapi spiritualitas yang berani “... To love in the face of hate, to overcome the hatred of a whole nation by demonstrating that Pentecost is something very different from the success-oriented American way of life." 11

Yang penting untuk disimak secara mendalam adalah pernyataan Hollenweger berkaitan dengan poin pertama, yaitu bahwa penekanan kekudusan tersebut sayangnya tidak tercatat di buku-buku sejarah dan teologi pentakostal yang diulas di edisi-edisi Eropa, bahkan soal tersebut juga dilupakan di Amerika sampai sebelum akhir abad ke-20. Hal ini merupakan salah satu bukti bahwa pentakostalisme lebih menekankan tradisi oral sehingga pengalaman spiritualitas dan pneumatologinya tidak didokumentasikan dan diteologikan secara akademis. Pentakostalisme awal kemudian berkembang secara luas di negara-negara Dunia Ketiga seperti Brazil, Chili, Sentral Amerika dan Karibia, Indonesia, Korea

\footnotetext{
${ }^{8}$ Cooper, "Laying the Foundations", $75-76$.

${ }^{9}$ Robeck Jr., The Azusa Street Mission and Revival, 29. Dikutip dalam Cooper, "Laying the Foundations", 75-76.

${ }^{10}$ Ibid.

${ }^{11}$ Hollenweger, "Priorities in Pentecostal Research", 9.
} 
[Selatan], perserikatan Soviet, serta negara-negara tertentu di Afrika. ${ }^{12}$ Namun, pentakostalisme ini selanjutnya berada dalam keadaan kondisi terpecah belah baik secara organisasi, misi, maupun pandangan teologianya; dan ini akhirnya menyebabkan tidak adanya organisasi pentakostal sedunia.

Di dalam tubuh pentakostalisme sampai dengan zaman sekarang ini dianut beragam pengajaran yang bercampur-baur, baik bercampur dengan kepercayaan dan kebudayaan lokal maupun pengaruh doktrin dari Protestantisme, terutama dari teologi Luther, Calvin, Arminius, dan lain-lain. Bahkan, dengan yakinnya Hollenweger mengatakan bahwa, "By and large Pentecostals adhere to a calvinistic pneumatology. It is strictly christological: in spite of what some critics of Pentecostals say. The Spirit of Pentecostalism has no dignity of its own. It is a Spirit which is constrained by the doctrine of the filioque (although the filioque is hardly ever discussed in Pentecostal theology). ${ }^{13}$ Meskipun demikian, perlu diberi catatan bahwa pentakostalisme tidak sekadar menerima kristologi Calvinis tetapi mengembangkannya sesuai dengan pengalaman spiritualitasnya. Ini dibuktikan dengan munculnya pengajaran di kalangan pentakostalisme dengan apa yang disebut Full Gospel ${ }^{14}$ dan the Jesus only. ${ }^{15}$ Oleh karena pentakostalisme mengikuti teologi dari arus utama, terutama kristologi Calvinismaka kristologinya berorientasi patriarkat $^{16}$ dan pneumatologinya pun ada dalam subordinasi kristologi.

\section{Ibid. \\ 13 Ibid.}

${ }^{14}$ Lihat Donald W. Dayton, "Theological Roots of Pentecostalism", dalam Pneuma: the Journal of the Society for Pentecostal Studies (Spring, 1980):4. Pengajaran Full Gospel berfokus pada pribadi Yesus Kristus dan isinya menekankan, "Jesus saves us according to John 3:16. He baptizes us with the Holy Spirit according to Acts 2:4. He heals our bodies according to James 5:15-15. And Jesus is coming again to receive us unto Himself according to I Thessalonians 4:16-17". Pengaruh gerakan kekudusan di abad ke-19, menambahkan pengajaran Full Gospel yang menekankan Yesus sebagai Pengudus (sanctifier) dalam pengakuan beberapa aliran Gereja-Gereja Pentakosta, khususnya di Amerika. Gereja-Gereja Pentakostal di konteks zaman sekarang ini menambahkan pengajaran mereka tentang Full Gospel yaitu mengenai Yesus pemberi berkat jasmani (teologi kemakmuran). Khusus untuk teologi kemakmuran ini dapat dilihat contohnya di dalam kasus Yoido Full Gospel Church yang dipimpin oleh Paul Yonggi Cho. Lihat Paul Yonggi Cho, Dimensi Keempat: Lebih Banyak Rahasia untuk Kehidupan Iman yang Berhasil, terjemahan Wimanjaya K. Liotohe, ed. ke 2 (Jakarta: Yayasan Pekabaran Injil Immanuel, 1986), 15. Bnd. Dongsoo Kim, "The Healing of Han in Korean Pentecostalism", dalam JPT 15 (1999): 123-139. Allan Anderson, tampaknya tidak setuju menyebut tokoh-tokoh seperti Essek W. Kenyon, Oral Robert, Kenneth Hagin, Norman Vincent Peale, Yonggi Cho masuk dalam aliran Pentakosta. Hal tersebut oleh karena penekanan Injil kemakmuran bukan menjadi bagian dalam teologi Pentakostal klasik di Amerika Utara. Namun demikian Anderson mengatakan bahwa di Benua Asia, Afrika, dan Amerika Latin perkembangan aliran Pentakostal, Karismatik, dan Pentakostal baru (new Pentakostal) bercampur baur termasuknya di dalamnya bersama-sama menekankan soal Injil kemakmuran (selain penekanan doktrin Full Gospel). Lihat Allan Anderson,

"Pentecostal Approaches to Faith and Healing", Review of Mission 91 (2002): 523-534.

${ }^{15}$ Disebut juga the Oneness Pentacostalism yang menekankan bahwa Allah adalah satu secara absolut dan tidak terbagi. Doktrin ini berseberangan dengan doktrin Trinitas

${ }^{16}$ Luther dan Calvin sama-sama menempatkan laki-laki sebagai superior dari perempuan. Akibat Hawa jatuh dalam dosa maka ini berakibat bagi perempuan keturunan selanjutnya kehilangan kesetaraannya dengan laki-laki; dan posisi yang seperti ini menjadikan juga perempuan sebagai ciptaan kedua (second in 
Selanjutnya muncul kegairahan baru dari para teolog Pentakostal modern untuk mengeksplorasi spiritualitas dan pengalaman Pentakostalisme awal dalam kajian teologi reflektif akademis yang bertanggungjawab. Kajian disiplin ilmu teologi yang baru ini disebut Renewal Theology. Amos Yong dalam artikelnya, "Pentecostal and Charismatic Theology," mengatakan bahwa Renewal Theology dimulai pada tahun 1960-an dengan ditandai adanya kesadaran historis di antara para sejarahwan Pentakosta untuk mendokumentasikan peristiwa-peristiwa kebangunan rohani dan gerakan misi Pentakostal di permulaan abad ke-20. ${ }^{17}$ Satu dekade kemudian berkembanglah apa yang disebut sebagai renewal biblical hermeneutics, yaitu pemahaman teologi yang baru tentang konsep pneumatologi, terutama yang berkaitan dengan kuasa Allah di dalam misi berdasarkan Injil Lukas dan Kisah Para Rasul. Pneumatologi ini berbeda dari teologi Paulus dalam suratsuratnya yang kental dengan konsep soteriologisnya.

Spiritualitas Pentakostalisme awal yang dikembangkan lebih lanjut oleh Renewal Theology sebenarnya mempunyai spirit yang sama dengan Teologi Feminis. Oleh karena Teologi Feminis juga melakukan the critique of the culture terhadap adanya realitas yang mensubordinasi perempuan terhadap laki-laki dan mendefinisikan perempuan sebagai kelompok inferior yang termarginalisasikan dari kehidupan publik baik dalam sistem kehidupan sosial budaya, ekonomi, maupun politik. ${ }^{18}$ Sebagaimana pentakostalisme awal dipengaruhi oleh spiritualitas kulit hitam, demikian juga Teologi Feminis, yang mula-mula dikembangkan oleh perempuan kulit putih, juga telah dipengaruhi gerakan Womanist theology dari perempuan kulit hitam di tahun 1980-an.

Menurut saya Renewal Theology berusaha untuk menghidupkan kembali spirit pentakostalisme awal dan meluaskan cakupan kajian-kajiannya secara akademis dari perspektif pneumatologis. ${ }^{19}$ Perspektif pneumatologis juga dapat dipakai dalam menyoroti masalah gender. Di sinilah titik temu dapat dijalin antara Teologi Feminis dan Renewal

creation), menurut Calvin. Luther dan Calvin sepakat bahwa perempuan itu inferior pada bagian tubuh, akal budi, moral, kehendak, dan kontrol dirinya dibandingkan laki-laki. Lihat Rosemary Radford Reuther, Women and Redemption: A Theological History, ed. ke-2 (Minneapolis: Fortress Press, 2012), 59; Rosemary Radford Ruether, Sexism and God-Talk: Toward a Feminist Theology (Boston: Beacon Press, 1993), 96-97.

${ }^{17}$ Lihat Amos Yong, "Pentecostal and Charismatic Theology," in The Routledge Companion to Modern Christian Thought, peny. Chad Meister and James Beilby (USA and Canada: Routledge, 2013).

${ }^{18}$ Lihat Rosemary Radford Ruether, "Eco-Feminism and Theology," in Ecotheology: Voices from South and North, peny. David G. Hallman, (Maryknoll, New York: Orbis Book, 1994), 199.

${ }^{19}$ Lihat kajian-kajian luas dari para teolog renewal theology: James K.A. Smith, Thinking in Tongues: Pentecostal Contributions to Christian Philosophy (Grand Rapids, MI: William B. Eerdmans, 2010); Amos Yong, "Discerning the Spirit (s): A Pentecostal-Charismatic Contribution to Christian Theology of Religions," in Journal of Pentecostal Theology Supplement Series 20, peny. John Christopher Thomas, Rieke D. Moore, dan Steven J. Land (England: Sheffield Academic Press, 2000); Amos Yong, The Spirit of Creation: Modern Science and Divine Action in the Pentecostal-Charismatic Imagination. (Grand Rapids, MI: Wm. Eerdmands, 2011). 
Theology. Sebelum kita mencoba mencari konvergensi dan divergensi dari kedua disiplin keilmuan tersebut terutama dalam hal metode dan penafsiran, maka kita perlu menelusuri selayang pandang tentang Gereja Isa Almasih yang notabene adalah gereja Pentakosta tetapi yang telah kehilangan akar spiritualitas pentakostalisme awal yang digawangi oleh Seymour. Selanjutnya bagaimana kedua disiplin ilmu tersebut dapat membantu Gereja Isa Almasih (juga Gereja-gereja Pentakosta lainnya) untuk setidaknya berefleksi dan berusaha menghayati kembali spiritualitas Pentakostalisme awal dalam kajian akademis dan hidup praksisnya. Topik-topik ini yang akan dicoba untuk dieksplorasi lebih lanjut dalam pembahasan ini.

\section{Gereja Isa Almasih Selayang Pandang}

Gereja Isa Almasih ${ }^{20}$ pada mulanya bernama Sing Ling Kauw Hwee (selanjutnya disingkat SLKH) berdiri pada 21 Juli 1946 di Semarang, Jawa Tengah dengan tokohnya bernama Pdt. Tan Hok Tjoan. Sing Ling berarti Roh Kudus dan Kauw hwee perhimpunan. Sebutan SLKH juga menunjukkan bahwa mayoritas jemaat mula-mula berasal dari etnis Tionghoa Peranakan Semarang dengan sistem keluarga bercorak patriarkat. Meskipun pada tahun 1920-an dan 1930-an terjadi gerakan pemuda secara nasional dan situasi ini berimbas juga pada munculnya gerakan emansipasi perempuan di tahun-tahun sesudahnya di berbagai kota di Indonesia termasuk Semarang, namun situasi ini hanya menyebabkan gerak perempuan lebih luas sedikit daripada sekadar kehidupan domestik di rumah tangga saja. $^{21}$

Organisasi perempuan terkenal di Semarang adalah $F u ~ N u$ Hui (Women's Association), yang didirikan pada tahun 1926 dan berfokus pada kegiatan bantuan sosial (charitable) dan rekreasi (recreational). ${ }^{22}$ Organisasi perempuan lainnya dalam skala kecil adalah organisasi perempuan Protestan bernama "Debora" yang mengkampanyekan

\footnotetext{
${ }^{20}$ Perubahan ini karena penyesuaian dalam konteks yang berbahasa Indonesia. Bahasa Alkitab dan penggunaan bahasa waktu itu menyebut Yesus Kristus sebagai Isa Almasih. Perubahan nama ini juga menunjukkan inklusivitas GIA terhadap etnis-etnis lainnya. Lihat Indrawan Eleeas, Gerakan Pentakosta Berkaitan dengan Sejarah dan Teologi Gereja Isa Almasih. (Semarang: Gereja Isa Almasih Pringgading, 2008).

${ }^{21}$ Lihat Donald Earl Willmott, The Chinese of Semarang: A Changing Minority in Indonesia. (Ithaca, New York: Cornell University Press, 1960), 283-284. Sebagaimana juga dikatakan oleh Oei Hien Tjhiang sebagai berikut: "Emancipation has very greatly changed the life of women. The field of their activities, which in the past was severely limited, has now become almost as wide as the field of activities of men. The recent world war seems to have speeded up this process of emancipation. In about fifty years the life of women has become as different as day from night." Lihat Oei Hien Tjiang, "Lain Dulu, Lain Sekarang”, dalam Star Weekly no. 528 (Feb. 11: 1956): 4. Dikutip dalam Willmott, The Chinese of Semarang, 283.

${ }^{22}$ Ibid., 285.
} 
pentingnya pengaturan kelahiran bagi perempuan di kota Semarang. ${ }^{23}$ Gerakan perempuan di tahun-tahun itu hampir sama seperti gerakan perempuan gelombang pertama di Amerika Utara di akhir abad ke-19 dan di awal abad ke-20, yang isu-isu perjuangannya meliputi pembaruan posisi perempuan di masyarakat, emansipasi, kemandirian ekonomi, dan kerja tanpa adanya keinginan untuk merombak sistem budaya masyarakat yang dikuasai sistem patriarkatisme. $^{24}$

Partisipasi perempuan untuk menjadi pemimpin tetaplah sulit pada awal abad ke20, termasuk di tahun 1946-an dan sesudahnya. Donald Earl Willmott, seorang sejarahwan yang meneliti komunitas Cina di Semarang, mengatakan, "Although many of the association ... Women have never played an important part in them. Women's branches and temporary women's committees of various organization have been established from time to time, primarily to help raise funds. Women are very rarely elected to leadership positions in competition with men, and whey they are, the positions are more honorary than functional." 25

Saat SLKH sebagai lembaga gereja diresmikan dan bersamaan itu juga majelis pertama kali dilantik pada tanggal 21 Juli 1946, sejarah mencatat bahwa semua anggota majelis adalah laki-laki. ${ }^{26}$ Memang perempuan sangat dilibatkan dalam pelayanan gerejawi saat itu namun tidak ada satu pun duduk dalam kepemimpinan di kemajelisan SLKH. ${ }^{27}$ Kemajelisan di SLKH menunjukkan sistem pemerintahan gerejanya bercorak Presbyterial dengan keunikan bahwa gembala jemaat sebagai pemimpinnya. Tata Gereja GIA sekarang menyebut sistem ini sebagai Presbyterial Sinodalkhas $G I A .{ }^{28}$ Sistem seperti ini tidak lazim seperti di gereja beraliran Pentakostal pada umumnya. Memang dulunya Pdt. Tan Hok Tjoan mempunyai kerjasama pelayanan dengan United Pentecostal Church namun ia tidak mau melegitimasikan persekutuan yang dipimpinnya di bawah organisasi Gereja tersebut. Tidak saja secara sistem organisasi berbeda dari gereja-gereja Pantekostal pada umumnya, tetapi ekspresi dan liturgi ibadah SLKH juga berbeda sama sekali. Ini sebenarnya

\footnotetext{
23 Ibid.

${ }^{24}$ Lihat Elisabeth Moltman-Wendel and Melanie A. May, "Feminism", in Dictionary the Ecumenical Movement, $2^{\text {nd }}$ edition, peny. Nicholas Lossky, Jose Miguez Bonino, John Pobee (Geneva: WCC Publications, 2002), 471; Linda Hogan, "Feminist theology", in Enclopedia of Christianity, peny. John Bowden (Oxford: University Press, 2005), 459.

${ }^{25}$ Willmott, The Chinese of Semarang, 285.

${ }^{26}$ Lihat Tan Hok Tjoan, Buku Peringatan Berdiri 10 Tahun dari 1946 - 1956 Geredja Isa Almasih (Sing Ling Kauw Hwee) di Indonesia. (Semarang: Geredja Isa Almasih, 1946), 7.

${ }^{27}$ Sinode Gereja Isa Almasih, Tan Hok Tjoan: Hidup untuk Memuliakan Allah. (Yogyakarta: Andi offset, 2012). Lihat bagian buku yang berjudul "Konsep Teologia Tan Hok Tjoan”, yang berbicara tentang peranan perempuan di SLKH.

${ }^{28}$ Sinode Gereja Isa Almasih, Tata Gereja. (Semarang: MPH Sinode GIA, 2008), 2.
} 
menunjukkan bahwa corak bergereja dan kepemimpinan GIA menyerupai corak bergereja dan kepemimpinan gereja arus utama pada umumnya. Willmott dalam observasinya mengatakan:

... Rev. Tan Hok Tjoan, is said to have a more intellectual and less emotional approach to religion. The service which he conducts are not characterized by the shouting and the emotional pitch of the mission church. Then, too, the Sing Ling Kauw Hwee is more broad-minded and less exclusive in its relations with outsiders. It participates in the join services of the combined Protestant churches of Semarang at Christmas and Easter. ${ }^{29}$

Apa yang dikatakan Hollewenger tentang pengaruh teologi gereja arus utama terhadap gereja-gereja Pentakostal terlihat jelas sekali dalam diri GIA dan kepemimpinan di dalamnya. Sampai sekarang ini tidak ada larangan atau dukungan secara eksplisit di dalam Tata Gereja 2008 terhadap perempuan menjadi pemimpin.

Pernah dalam sejarah ada dua perempuan, Pdt. Ertin Tan di GIA Cirebon dan Pdt. Susana Sulbiah, yang menjadi gembala jemaat namun setelah keduanya turun maka lama sekali tidak ada lagi perempuan pemimpin lagi yang muncul. Sebuah Gereja Isa Almasih di kota kecil Weleri, Kendal, di mana penulis juga sebagai salah satu pendeta tugas khusus dari jemaat itu, para majelis dan jemaatnya gamang dan akhirnya mempertimbangkan ulang pengangkatan terhadap perempuan pendeta mereka sebagai gembala jemaat. Dalam kurun waktu lima tahun terakhir ini muncullah beberapa perempuan pendeta yang menjadi gembala di lingkungan GIA meskipun jumlahnya masih sedikit sekali. Di beberapa GIA yang jumlah jemaatnya di atas lima ratus anggota, para wakil gembala jemaatnya adalah laki-laki. Di gereja-gereja tersebut juga terjadi ketidaksetaraan mengenai hak-hak yang dapat diterima oleh perempuan pendeta dibandingkan mereka laki-laki pendeta, misalnya dalam kesempatan mendapat fasilitas perumahan dan tunjangan sosial lainnya. Di level pimpinan Majelis Daerah tidak ada satu pun perempuan pemimpin. Sementara di level Sinode, perempuan pemimpin selalu hanya sekitar satu-dua orang saja di antara sekian banyak laki-laki pemimpin dan juga kebanyakan perempuan pemimpin itu datangnya dari jemaat awam dan jabatannya sebagai bendahara atau dalam pelayanan sosial.

Oleh karena tidak ada kekuatan doktrin bersama yang mengikat yang dipegang oleh Sinode GIA maka akibatnya begitu banyak versi teologi yang berkembang di lingkup GIA. Namun secara keseluruhan pendekatan pneumatologis berorientasi kepada, sebagaimana dikategorikan oleh Hollenweger "the ideengeschichtliche ... This approach to Pentacostal

${ }^{29}$ Willmott, The Chinese of Semarang, 234. 
history focuses on the history of theological ideas; in particular on the idea of the baptism of the Holy Spirit with the 'initial evidence'of speaking in tongues. Therefore the start of Pentecostalism is seen in Parham's Bible school where this doctrine was formulated for the first time. ${ }^{\prime 30}$ Di tahun 1990-an, ada perdebatan di lingkup GIA tentang bahasa roh sebagai bukti awalnya adalah baptisan Roh Kudus dan bahasa roh sebagai salah satu karunia rohani. Sampai sekarang GIA masih merayakan ibadah sepuluh hari sebelum perayaan hari Pentakosta dan banyak jemaat GIA masih merindukan pengalaman berbahasa roh meski pada kenyataannya hanya sebagian kecil saja jemaat yang dapat berbahasa roh.

Orientasi pneumatologi GIA jelas sekali lebih cenderung ke ideengeschichtliche ${ }^{31}$ daripada realgeschichtliche. Orientasi ini juga menjadikan pneumatologis GIA sangat cenderung ke Parham daripada ke Seymour. Apakah yang mesti GIA lakukan sekarang ini supaya sebagai Gereja-Nya GIA dapat menjadi peka untuk membaca the signs of the times, termasuk di dalamnya isu-isu mengenai kesetaraan laki-laki dan perempuan, walau GIA sebenarnya sudah sangat tertinggal sekali untuk merespons isu ini? Tentunya, lebih baik terlambat merespons daripada tidak memberi respon sama sekali baik melalui kata-kata atau tulisan maupun dalam bentuk praksis atau aksi.

Orientasi ke ideengeschichtliche perlu diperbarui dengan tafsir pneumatologis masa kini yang kembali kepada akar spiritualitas Pentakosta bahwa Allah menjadikan laki-laki dan perempuan nabi-nabi-Nya yang setara dalam konteks pelayanan, termasuk dalam kepemimpinan di internal gerejawi dan di konteks yang lebih luas yaitu masyarakat dan bangsa. ${ }^{32}$ Yang terpenting juga bagi GIA adalah kembali ke orientasi pneumatology realgeschichtliche karena orientasi ini terbuka bagi kesetaraan gender. Dari sudut pandang perspektif ini maka perlu di dialogkan Teologi Feminis dan Renewal Theology agar dapat memberikan sumbangan teologis dan praksis bagi GIA dan juga Gereja Pentakosta secara umumnya.

\footnotetext{
${ }^{30}$ Hollenweger, "Priorities in Pentecostal Research", 10.

${ }^{31}$ Pengakuan Iman dan Pengajaran Sinode GIA Pasal 6:9, “Aku percaya akan Baptisan Roh Kudus dengan tanda bahasa roh Glosolali ... Di Pengakuan Iman tersebut tertulis juga adanya ayat-ayat yang diambil juga dari Pengakuan Iman Rasuli seperti kepercayaan kepada Allah Tritunggal (ayat 2). Lihat Sinode Gereja Isa Almasih, Tata Gereja, 5-7.

${ }^{32}$ Topik ini tidak akan dieksplorasi lebih jauh dalam tulisan ini karena keterbatasan halaman yang disediakan untuk paper ini. Saya pikir apa yang dikerjakan oleh James K.A. Smith saat membahas kontribusikontribusi Pentakostal kepada filsafat Kristen dalam konteks menggemakan isu-isu pneumatologis kontemporer mungkin dapat memberi tafsiran yang baru terhadap bahasa roh. Lihat James K.A. Smith, Thinking in Tongues: Pentecostal Contributions to Christian Philosophy. (Grand Rapids, MI: William B. Eerdmans Publishing Company, 2010).
} 


\section{Metode dan Tafsir Pneumatologis dari Teologi Feminis ${ }^{33}$ dan Renewal Theology}

Metode berteologi bagi dua disiplin ilmu di atas diikat dan dilambari pneumatologi yang menegaskan bahwa karya Roh kudus memberikan kuasa kepada laki-laki dan perempuan untuk dapat mengerjakan Missio Dei. Berbeda dengan bahasa metafora yang menggambarkan dua pribadi Trinitas Bapa dan Putera sebagai laki-laki atau maskulin, sebaliknya Roh Kudus feminin. ${ }^{34}$ Beberapa teolog feminis ${ }^{35}$ memaparkan Roh Allah dalam metafora feminin sebagai pilihan untuk membuat perimbangan terhadap bahasa maskulin tentang Allah sebagai Bapa yang cenderung memperkuat stereotip gender di masyarakat patriarkat. ${ }^{36}$ Tujuannya pemunculan ini untuk membentuk kesadaran kolektif yang baru dan kuat bagi jati diri perempuan dan kemudian kesadaran itu dapat dijadikan dasar untuk mengkonstruksi realitas yang inklusif serta mendorong perjuangan perempuan melawan ketidakadilan sistem patriarkat.

Gambaran metafora Roh Kudus yang diasosiasikan feminin misalnya berkaitan dengan hikmat (English: wisdom; Greek: Sophia) yang menurut Elizabeth Johnson, menekankan model hubungan keterikatan yang mendalam (inner-relatedness) yang tidak memberikan ruang adanya subordinasi dan stereotip gender sebagaimana dalam masyarakat patriarkat. ${ }^{37}$ Jürgen Moltmann mengatakan bahwa feminitas dan keibuan Roh

${ }^{33}$ Beberapa teolog feminis tertentu saja yang akan dipakai teorinya untuk saling menyokong dan melengkapi dengan renewal theology saat membicarakan soal perempuan pemimpin.

${ }^{34}$ Memang kata roh atau spirit tidak secara spesifik berorientasi pada jender tertentu seperti jelas dalam bahasa Metafora untuk Bapa dan Putera. Spirit dalam bahasa Ibrani adalah rûach secara gramatika bentuknya feminin meski diberi catatan bahwa konsep kepribadian Roh Kudus belum berkembang di Perjanjian Lama. Di Perjanjian Baru dipakai kata pneuma (bahasa Yunani) secara gramatika berbentuk neuter dan bahasa Inggris juga mengkategorikannya sebagai neuter. Hanya di Injil Yohanes sebutan untuk Spirit sebagai Parakletos secara gramatika berbentuk maskulin. Tradisi Latin menyebut Spiritus (spirit) juga dalam bentuk maskulin. Menurut Clark H. Pinnock para teolog di masa lalu seperti Aphrahat dalam tulisannya berjudul Demonstration 6:14, St. Teresa, dan John of the Cross menggambarkan Roh Kudus dalam metafora feminin. Pinnock mengatakan, "Using a feminine pronoun would pick up the grammatical feminine of the Hebrew and honor female like functions of the Spirit, such as birthing, nurturing, grieving and sheltering. It would also recognize Spirit as associated with such feminine images as wisdom and the shekinah presence. Spirit fosters receptivity in our hearts vis a. vis the Father and is often femininelike in experience-coming as gentle dove, mother eagle, and pour-out love. Lihat Clark H. Pinnock, Flame of Love: A Theology of The Holy Spirit (Downers Grove, IL: InterVarsity Press, 1996), 15-16.

${ }^{35}$ Tokoh-tokohnya seperti Virginia Ramey Mollenkott, The Divine Feminine:The Biblical Imagery of God as Female. (New York: Crossroad, 1987); Sallie McFague, Models of God: Theology for an Ecological, Nuclear Era. (Philadelphia: Fortress Press, 1987) dan Metaphorical Theology: Models of God in Religious Language. (Philadelphia: Fortress Press, 1982), dan juga Elizabeth A. Johnson, She Who Is: The Mystery of God in Feminist Theological Discourse. (New York: Crossroad, 1994).

${ }^{36}$ Lihat Mary Daly, Beyond God the Father, Toward a Philosophy of Women's Liberation. (Boston: Beacon Press, 1973), 11-12 dan Carol P. Christ dan Judith Plaskow, peny., "Introduction," dalam Women Spirit Rising: A Feminist Reader in Religion (San Fransisco: Harper Collin Publishers, 1998), 1. Para teolog ini setuju bahwa konsep Allah sebagai laki-laki melegitimasi superioritas dan kepemimpinan laki-laki di keluarga, Gereja, dan masyarakat.

${ }^{37}$ Elizabeth A. Johnson, She Who Is: The Mystery of God in Feminist Theological Discourse. (New York: Crossroad, 1994), 51-53, 143-144, dan 215. 
Kudus yang melahirkan baru (Yoh. 3:1-8) menjadikan laki-laki dan perempuan berada dalam sebuah komunitas persaudaraan baru yang bebas dan setara. ${ }^{38}$ Roh Kudus berkarya melahirkan kembali (Yoh. 3:1-8) laki-laki dan perempuan agar memiliki kemanusiaan seutuhnya sebagai ciptaan baru yang tidak saling mensubordinasi satu sama lainnya.

Teologi Feminis dan Renewal theology tidak setuju dengan konsep yang menempatkan pembicaraan pneumatologi tersubordinasi kristologi. Sebagaimana selama ini telah terjadi saat kajian pneumatologi menjadi the Cinderella of Theology, ${ }^{39}$ sebagaimana yang terutama terjadi dikalangan Gereja Katolik sebelum Vatikan II dan Gereja Protestan sebelum terbuka terhadap gerakan Pentakostal-Karismatik. Teologi Feminis dan Renewal Theology juga tidak setuju dengan konsep Spirit Christology yang disinyalir oleh Rosemary Radford Ruether ada di dalam gerakan yang diprakarsai oleh Montanus, Joachim of Fiore, Prous Boneta, the Shakers, dan Mary Baker Edi, yang mencoba memisahkan hubungan pribadi Sang Anak dan Roh Kudus. ${ }^{40}$

Teologi Feminis dan Renewal Theology menyetujui hubungan yang setara antara Yesus Kristus dan Roh Kudus tanpa tersubordinasi dan terseparasi satu sama lainnya. Untuk menemukan hal ini maka mau tidak mau harus melihat Yesus Kristus sebagaimana dikisahkan oleh Injil Sinoptik. Ia adalah Mesias-Hamba yang diurapi oleh Roh Kudus yang menyampaikan pesan dan praksis yang berpihak kepada yang lemah dan marginal, termasuk perempuan di dalamnya. Pendekatan kristologi semata-mata tanpa sentuhan pneumatologi, menurut Amos Yong akan menemui jalan buntu apalagi ketika kristologi yang disampaikan adalah doktrin-doktrin kristologi yang eksklusif dengan ruh triumphalistik yang mendasarinya. ${ }^{41}$

Teologi Feminis dan Renewal Theology percaya bahwa kekristenan perlu terbuka terhadap nilai-nilai positif dari kebudayaan, kepercayaan, dan agama-agama lainnya. Hal ini karena Roh Kudus berkarya secara luas. Sinkretisme bagi kekristenan tidak menjadi masalah sejauh itu dilakukan secara bertanggungjawab untuk mendukung dan memperkuat keadilan dan kesetaraan bagi perempuan. Hollenweger menyatakan sinkretisme tidak dapat

\footnotetext{
${ }^{38}$ Jürgen Moltmann, The Source of Life: the Holy Spirit and the Theology of Life, terjemahan Margaret Kohl (London: SCM, 1997), 27.

${ }^{39}$ Veli-Matti Kärkkäinen, Pneumatology : The Holy Spirit in Ecumenical, International, and Contextual Perspective (Grand Rapids, Michigan: Baker Academic, 2002), 16. Tambahan, menurut saya pembicaraan tentang pneumatologi telah mengalami defisit terutama di Gereja-Gereja Barat yang sangat kristosentris dan ini berbeda dari Gereja-Gereja Ortodok. Sedangkan di lingkungan Gereja-Gereja Pentakosta cenderung ke kristomonisme sebagaimana nampak dalam doktrin Full Gospel dan the Jesus only.

${ }^{40}$ Lihat detail penjelasannya di dalam Rosemary Radford Ruether, Sexism and God-Talk: Toward a Feminist Theology. (Boston: Beacon Press, 1993), 130 -135.

${ }^{41}$ Lihat Amos Yong, Beyond the Impasse: Toward a Pneumatologal Theology of Religions. (Grand Rapids and Cumbria: Baker Academic and Paternoster Press, 2003).
} 
dihindari dan itu ditulis oleh Alkitab sendiri seperti misalnya model pembangunan Bait Suci Israel mengikuti arsitektur Bangsa Kanaan dan para ahli bangunannya dari mereka juga; dan juga seperti kisah para Majus dari Timur yang menemui bayi Yesus dipalungan berdasarkan pengetahuan kepercayaan astrologi mereka. ${ }^{42}$

Hollenweger percaya bahwa Roh Kudus sebagai rûach Yahwe, pemberi hidup, dan Roh penopang hidup dari Allah, berdasarkan Kisah Para Rasul 2:17, “ ... Poured out on all flesh, not just on Christian or religious flesh." 43 Ia setuju dengan konsep J. Moltmann tentang panentheism yang mengatakan bahwa “... God's Spirit is both person and lifegiving power ... He (or she, rûach is feminine) is present in all life: not just in Christian life.” ${ }^{44}$ Dari segi Teologi Feminis, sinkretisme untuk mengokohkan perjuangan perempuan juga tidak menjadi masalah. ${ }^{45}$ Malahan tampaknya Teologi Feminis jauh lebih berani dalam memasuki ranah sinkretisme dibandingkan Renewal Theology. Juga untuk isu-isu lainnya seperti perjuangan kesetaraan bagi kelompok lainnya seperti Lesbian, Gay, Bisexual, Trans, and Queer (LGBTQ).

Baik Teologi Feminis maupun Renewal Theology menaruh kekritisan terhadap Kitab Suci Kristen yang ditulis dalam budaya laki-laki. Ambil contoh pada teks-teks seperti 1 Korintus 14:26-40 dan 1 Timotius 2:8-15. Teks-teks ini bukan misogynist namun harus ditafsir melalui strategi feminis revisionis dengan melakukan "depatriarkatisasi" ayat-ayat tersebut. Elisabeth Schüssler Fiorenza mengatakan, "A feminist revisionist strategy asserts that biblical texts themselves are not misogynist ... Consequently, the Bible must be 'depatriarchalized' because, correctly understood, it actually fosters the liberation of women." ${ }^{46}$ Fiorenza mengatakan bahwa teks-teks tersebut tidak melarang perempuan mengajar di tempat publik tetapi melarang pengajaran yang salah yang dimunculkan oleh perempuan waktu itu. Jadi persoalannya bukan pada kepemimpinan perempuan tetapi pada soal pengajaran yang tidak benar waktu itu yang Paulus tegur.

Sedangkan pendekatan pneumatologis Renewal Theology mengatakan bahwa Paulus tidak pernah menempatkan posisi perempuan tersubordinasi dari laki-laki karena

\footnotetext{
${ }^{42}$ Hollenweger, "Priorities in Pentecostal Research", 15.

${ }^{43}$ Ibid., 17.

${ }^{44}$ J. Moltmann, Gott in der Schöpfung. Oekologische Schöpfungslehre (Munich: Kaiser, 1985). Dikutip dalam Hollenweger, "Priorities in Pentecostal Research", 17.

${ }^{45}$ Lihat Carol P. Christ, "Why Women Need the Goddes: Phenomenological, Psychological, and Political Reflections", and Judith Plaskow, "The Coming of Lilith: Toward a feminist Theology," in Women Spirit Rising: A Feminist Reader in Religion, peny. Carol P. Christ dan Judith Plaskow (San Fransisco: Harper Collin Publishers, 1998).

${ }^{46}$ Elisabeth Schüssler Fiorenza, But She Said: Feminist Practices of Biblical Interpretation. (Boston: Beacon Press, 1992), 23.
} 
semua tulisan Paulus untuk menilai hubungan laki-laki dan perempuan terpusat di Galatia $3: 28$, “... Tidak ada laki-laki atau perempuan, karena kamu semua adalah satu di dalam Kristus". Teks ini adalah Magna Carta of Humanity, a charter of Christian equality ${ }^{47}$ yang nilainya sejajar dengan Kisah Para Rasul 2:17. Jika ada teks-teks seperti di 1 Korintus 14:26-40 dan 1 Timotius 2:8-15 maka teks-teks itu tidak dapat dijadikan proof-text bahwa untuk selamanya posisi perempuan akan tersubordinasi dari laki-laki. Teks-teks itu harus dipahami bahwa situasi sosial waktu itu tidak memungkinkan untuk perempuan menjadi pemimpin karena Paulus harus menjaga perempuan agar tidak mendapat masalah lebih lanjut dalam masyarakat patriarkatsentris dan androsentris waktu itu yang belum terbuka terhadap kebebasan dan kesetaraan laki-laki dan perempuan. ${ }^{48}$ Roh Kudus memberikan hikmat pengajaran kepada Paulus untuk merespons secara etis teologis terhadap suatu konteks tertentu saja waktu itu. Nils-Olov Nilsson dalam tulisannya, The Debate on Women's Ministry in the Swedish Pentecostal Movement: Summary and Analysis, mengatakan sebagai berikut:

It is easy to understand why women during so many centuries could not live out their Christian freedom without the support from an understanding society. In this special case, when a few of the Pauline texts on women's ministry apparently contradict each other-comparing the following texts: Gal. 3:28-29; 1 Tim. 2:9-1; 1 Cor. 14:34-35 and 1 Cor. 14:26-we should be careful not to arrive at too hasty conclusions that Paul changed his views from time to time or succumbed to the pressures from some "anti-feminist" or Jewish groups in the local churches. For example, what is reflected in 1 Cor. 14 and 1 Tim. 2 are two completely different problems in the apostolic local churches, which had to be dealt with distinctively. These texts are colored by values and customs taken from the apostolic era and cannot be literally transferred or applied to the modern church or society without proper contextualization. ${ }^{49}$

\footnotetext{
${ }^{47}$ Lihat Stanley Grenz and Denise Muir Kjesbo, Woman in the Church, A BiblicalTheology of Women in Ministry. (Downers Grove,IL InterVarsity Press, 1995). Perlu juga diberi catatan di sini bahwa teologi feminis sering menilai bahwa Gal. 3:28 bukanlah murni dari Paulus dan juga teks itu cenderung ditafsir kesetaraan laki-laki dan perempuan terjadi dalam level spiritualitas saja dan di akhir zaman. Lihat Rosemary Radford Ruether, Women and Redemption: A Theological History. (Minneapolis: Fortress Press, 2012), 24-35.

${ }^{48}$ Nils-Olov Nilsson, "The Debate on Women's Ministry in the Swedish Pentecostal Movement: Summary and Analysis", dalam Pneuma: The Journal of the Society for Pentecostal Studies 22, no. 1(Spring, 2000): 76; dan Lihat Antoinnete L. Brown, "Exegesis of I Corinthian XIV., 34, 35; and I Timothy II.,11.12”, dalam Oberlin Quarterly Review 5(1849): 372. Fiorenza setuju dengan Brown yang menjelaskan bahwa masalah-masalah yang melatarbelakangi teks-teks tersebut adalah, "the depravity and low status of women in the surrounding culture of Judaism and Greco-Roman antiquity and the misbehavior of the Church."

${ }^{49}$ Lihat Nils-Olov Nilsson, "The Debate on Women's Ministry in the Swedish Pentecostal Movement: Summary and Analysis”, dalam Pneuma: The Journal of the Society for Pentecostal Studies 22,
} no. 1 (Spring, 2000): 61-83. 
Perlu diberi catatan akhir di tulisan ini bahwa kelompok feminis radikal dan liberal setuju dengan teologi Pembebasan yang memahami karya Roh Kudus terlibat dalam perubahan struktur-struktur yang tidak adil melalui perjuangan atau revolusi sosial. ${ }^{50}$ Sedangkan Renewal Theology tampaknya lebih mementingkan transformasi dari dalam masyarakat melalui penguatan sistem nilai dan proses dinamis yang menuju pada transformasi yang damai oleh kuasa dan kekuatan Roh Kudus yang berkarya dalam diri orang-orang percaya. ${ }^{51}$

\section{Kesimpulan}

Kesempatan perempuan untuk menjadi pemimpin terutama di puncak hierarki kepemimpinan seperti menjadi gembala jemaat (juga jabatan sebagai ketua Majelis Daerah dan Sinode) di lingkungan Sinode GIA akan tetap memperoleh tantangan yang besar sampai kapan pun selama Sinode GIA tidak terbuka kepada pneumatologi yang berorientasi kepada realgeschichtliche dan membuka diri terhadap Teologi Feminis dan renewal theology. Sayang sekali bahwa GIA dan gereja-gereja Pentakostal pada umumnya justru terjebak dalam doktrin kristologi yang bias gender dan melupakan pentakostalisme awal yang dimotori oleh Seymour. Munculnya Teologi Feminis dan Renewal Theology memberikan secercah harapan bagi munculnya pneumatologi yang biblikal (ortodok), terkait dengan pesan dan praksis Yesus Kristus, fungsional, dan relevan. Kedua teologi di atas ini memberikan dasar-dasar spiritualitas dan teologi tentang kebebasan dan kesetaraan antara laki-laki dan perempuan dalam hal kepemimpinan di gereja, bahkan juga di masyarakat.

\section{Kepustakaan}

Anderson, Allan. "Pentecostal Approaches to Faith and Healing". Review of Mission 91 (2002): 523-534.

An Introduction to Pentecostalism: Global Charismatic Christianity. Cambridge: Cambridge University Press, 2004.

Brown, Antoinnete L. "Exegesis of I Corinthian XIV., 34, 35; and I Timothy II.,11.12", Oberlin Quarterly Review 5 (1849): 372.

Christ, Carol P. dan Plaskow, Judith, peny. "Introduction," in Women Spirit Rising: A Feminist Reader in Religion. San Fransisco: Harper Collin Publishers, 1998.

\footnotetext{
${ }^{50}$ Kärkkäinen, Pneumatology, 154-158.

${ }^{51}$ Bnd. Nilsson, "The Debate on Women's Ministry", 77.
} 
Christ, Carol P. "Why Women Need the Goddes: Phenomenological, Psychological, and Political Reflections", and Plaskow, Judith. "The Coming of Lilith: Toward a feminist Theology," in Women Spirit Rising: A Feminist Reader in Religion, peny. Carol P. Christ dan Judith Plaskow. San Fransisco: Harper Collin Publishers, 1998.

Cho, Paul Yonggi. Dimensi Keempat: Lebih Banyak Rahasia untuk Kehidupan Iman yang Berhasil, terjemahan Wimanjaya K. Liotohe, ed. ke 2. Jakarta: Yayasan Pekabaran Injil Immanuel, 1986.

Cooper, Valerie C. "Laying the Foundations for Azusa Black Women and Public Ministry in the Nineteenth Century", in Afro-Pentecostalism Black Pentecostal and Charismatic Christianity in History and Culture, peny. Amos Yong and Estrelda Y. Alexandera. New York and London: New York University Press, 2011.

Daly, Mary. Beyond God the Father, Toward a Philosophy of Women's Liberation. Boston: Beacon Press, 1973.

Dayton, Donald W. "Theological Roots of Pentecostalism". Pneuma: the Journal of the Society for Pentecostal Studies (Spring, 1980): 4.

Eleeas, Indrawan. Gerakan Pentakosta Berkaitan dengan Sejarah dan Teologi Gereja Isa Almasih. Semarang: Gereja Isa Almasih Pringgading, 2008.

Elisabeth Moltman-Wendel and May, Melanie A. "Feminism", in Dictionary the Ecumenical Movement, 2nd edition, peny. Nicholas Lossky, Jose Miguez Bonino, John Pobee. Geneva: WCC Publications, 2002.

Fiorenza, Elisabeth Schüssler. But She Said: Feminist Practices of Biblical Interpretation. Boston: Beacon Press, 1992.

Grenz, Stanley and Kjesbo, Denise Muir. Woman in the Church, A BiblicalTheology of Women in Ministry. Downers Grove,IL InterVarsity Press, 1995.

Hogan, Linda. "Feminist theology", in Enclopedia of Christianity, peny. John Bowden. Oxford: University Press, 2005.

Hollenweger, Walter J. The Pentecostals. Peabody MA: Hendrickson Publishers, 1972.

"Priorities in Pentecostal Research: Historiography, Missiology, Hermeneutics, and Pneumatology", dikutip dalam Experiences of the Spirit: Conference on Pentecostal and Charismatic Research in Europe at Utrecht University 1989, peny. Jan A.B. Jongeneel. Frankfurt am Main: Peter Lang,1989.

Johnson, Elizabeth A. She Who Is: The Mystery of God in Feminist Theological Discourse. New York: Crossroad, 1994.

Kärkkäinen, Veli-Matti. Pneumatology: The Holy Spirit in Ecumenical, International, and Contextual Perspective. Grand Rapids, Michigan: Baker Academic, 2002.

McFague, Sallie. Metaphorical Theology: Models of God in Religious Language. Philadelphia: Fortress Press, 1982.

. Models of God: Theology for an Ecological, Nuclear Era. Philadelphia: Fortress Press, 1987.

Mollenkott, Virginia Ramey. The Divine Feminine: The Biblical Imagery of God as Female. New York: Crossroad, 1987.

Moltmann, J. Gott in der Schöpfung. Oekologische Schöpfungslehre. Munich: Kaiser, 1985. 
Moltmann, Jürgen. The Source of Life: the Holy Spirit and the Theology of Life, terjemahan Margaret Kohl. London: SCM, 1997.

Nilsson, Nils-Olov. "The Debate on Women's Ministry in the Swedish Pentecostal Movement: Summary and Analysis", Pneuma: The Journal of the Society for Pentecostal Studies 22, no. 1 (Spring, 2000): 61-83.

Pinnock, Clark H. Flame of Love: A Theology of The Holy Spirit. Downers Grove, IL: InterVarsity Press, 1996.

Robeck, Cecil M. J. The Azusa Street Mission and Revival: The Birth of the Global Pentecostal Movement. Nashville: Nelson Reference and Electronic, 2006.

Ruether, Rosemary Radford. Sexism and God-Talk: Toward a Feminist Theology. Boston: Beacon Press, 1993.

."Eco-Feminism and Theology," in Ecotheology: Voices from South and North, peny. David G. Hallman. Maryknoll, New York: Orbis Book, 1994. Minneapolis: Fortress Press, 2012.

Sinode Gereja Isa Almasih. Tata Gereja. Semarang: MPH Sinode GIA, 2008.

Andi offset, 2012.

Tan Hok Tjoan: Hidup untuk Memuliakan Allah. Yogyakarta:

Smith, James K.A. Thinking in Tongues: Pentecostal Contributions to Christian Philosophy. Grand Rapids, MI: William B. Eerdmans Publishing Company, 2010.

Tjiang, Oei Hien. “Lain Dulu, Lain Sekarang”, Star Weekly, no. 528 (1956): 4.

Tjoan, Tan Hok. Buku Peringatan Berdiri 10 Tahun dari 1946 - 1956 Geredja Isa Almasih (Sing Ling Kauw Hwee) di Indonesia. Semarang: Geredja Isa Almasih, 1946.

Willmott, Donald Earl. The Chinese of Semarang: A Changing Minority in Indonesia. Ithaca, New York: Cornell University Press, 1960.

Yong, Amos. "Discerning the Spirit (s): A Pentecostal-Charismatic Contribution to Christian Theology of Religions," Journal of Pentecostal Theology Supplement Series 20, peny. John Christopher Thomas, Rieke D. Moore, dan Steven J. Land. England: Sheffield Academic Press, 2000.

. Beyond the Impasse: Toward a Pneumatologal Theology of Religions. Grand Rapids and Cumbria: Baker Academic and Paternoster Press, 2003.

The Spirit of Creation: Modern Science and Divine Action in the Pentecostal-Charismatic Imagination. Grand Rapids, MI: Wm. Eerdmands, 2011.

. "Pentecostal and Charismatic Theology," in The Routledge Companion to Modern Christian Thought, peny. Chad Meister and James Beilby. USA and Canada: Routledge, 2013. 